\title{
Primary Culture of Neonatal Rat Olfactory Neurons
}

\author{
Gabriele V. Ronnett, ${ }^{1,2}$ Lynda D. Hester, ${ }^{2}$ and Solomon H. Snyder ${ }^{2}$ \\ 'Department of Neurology and 'Departments of Neuroscience, Pharmacology and Molecular Sciences, and Psychiatry \\ and Behavioral Sciences, Johns Hopkins University School of Medicine, Baltimore, Maryland 21205
}

\begin{abstract}
We have prepared primary cultures of purified neonatal rat olfactory neurons. Dissociated olfactory epithelial cells are maintained in modified Eagle's medium with D-valine, cytosine arabinoside, and NGF. NGF is required for neuronal survival. Immunohistochemical staining is positive for the neuronal markers vimentin, olfactory marker protein, and neuron-specific enolase, but negative for the glial markers, glial fibrillary acidic protein, and S-100 protein. Physiologic concentrations of odorants stimulate CAMP accumulation in the cells. Because of their morphology, biochemical composition, and responsiveness to odorants, these cells should enhance olfactory investigations.
\end{abstract}

Olfactory transduction discriminates with great accuracy and sensitivity between a multitude of volatile, low-molecular-weight compounds (Lancet, 1986; Snyder et al., 1988), but compared to visual transduction, it is relatively poorly understood. One difficulty lies in the heterogeneity of the olfactory epithelium in which the olfactory neurons reside. The olfactory primary sensory neurons are located in a pseudostratified columnar epithelium consisting of three principal cell types (Graziadei, 1971). The sustentacular or supportive cells resemble glial cells and stretch from the epithelial surface to the basal lamina. Cell bodies of the sensory neurons lie at various levels in the epithelial layer and extend apical dendrites to the surface of the epithelium and unmyelinated axons through the basal lamina. The third cell type, the basal cell, underlies the receptor neurons and is thought to serve as a precursor population from which new olfactory neurons can arise. Isolation of receptor neurons from these other cell types has been difficult, thereby limiting ability to perform biochemical analysis.

Several attempts have been made to obtain populations of primary olfactory neurons. Initial efforts employed in vitro culture of the entire olfactory epithelium (Noble et al., 1984; Gonzales et al., 1985). $N$-ethylmaleimide has been used to dissociate olfactory epithelium cells into single cells, which, however, lose excitable properties (Kleene and Gesteland, 1981). Hirsch and Margolis (1979) have employed enzymatic dissociation followed by general mechanical disruption, with dissociated cells

Received July 31, 1990; revised Nov. 28, 1990; accepted Dec. 4, 1990.

We thank Dr. Frank Margolis for antibody to olfactory marker protein, Dr. Douglas Murphy for anti-tubulin antibody, and Dr. Karen Braas for NG-108 cells. This work was supported by U.S. Public Health Service Grants NS-01231 to G.V.R. and DA-00266, by Research Scientist Award DA-00074 to S.H.S., by a grant of International Flavors and Fragrances, and by a gift from Bristol-MyersSquibb Company.

Correspondence should be addressed to Solomon H. Snyder, M.D., Johns Hopkins University School of Medicine, Department of Neuroscience, 725 North Wolfe Street, Baltimore, MD 21205.

Copyright (C) 1991 Society for Neuroscience $0270-6474 / 91 / 111243-13 \$ 03.00 / 0$ centrifuged through a BSA gradient, yielding a partially purified population of cells. Others (Calof and Chikaraishi, 1989; Pixley and Pun, 1990) have devised methods to isolate small numbers of embryonic olfactory neuronal cells for lineage analysis and electrophysiologic studies.

We now describe a procedure permitting primary culture in relatively pure form of neonatal rat olfactory neurons. This technique involves enzymatic dissociation of the olfactory epithelium followed by mechanical disruption and selection of the desired neuronal cells with specific substrates and selective medium. These cells are highly responsive to low physiologic levels of odorants.

\section{Materials and Methods}

Primary culture of olfactory neurons. Approximately three litters or 2832 pups were used per preparation. The 2-3-d-old rat pups were killed by decapitation, and olfactory tissue was dissected and immediately placed in modified Eagle's medium (MEM) containing $4.8 \mathrm{gm} / \mathrm{liter}$ HEPES buffer, designated MEM-AIR (Fig. 1). The turbinates were transferred twice through fresh MEM-AIR to minimize contamination. Tissue was then centrifuged at $700 \times g$ for $7 \mathrm{~min}$. After the supernatant was decanted, the tissue was minced to achieve tissue fragments of approximately $1 \mathrm{~mm}$ in size, resuspended in MEM-AIR, and centrifuged at $500 \times \mathrm{g}$ for $7 \mathrm{~min}$. Tissue was then placed in $30 \mathrm{ml}$ MEM-AIR containing $1 \%(w / v)$ BSA, radioimmunoassay (RIA) grade (Sigma, St. Louis, MO), $1 \mathrm{mg} / \mathrm{ml}$ hyaluronidase (Sigma), $50 \mu \mathrm{g} / \mathrm{ml} \mathrm{DNAse} \mathrm{(Sigma),}$ $1 \mathrm{mg} / \mathrm{ml}$ collagenase (Worthington Biochemicals, Freehold, NJ), and 5 $\mathrm{mg} / \mathrm{ml}$ dispase (Boehringer-Mannheim Biochemicals, Indianapolis, IN) and incubated with agitation for $1 \mathrm{hr}$ at $37^{\circ} \mathrm{C}$. At the end of incubation, the cell suspension was triturated ten times with a $10-\mathrm{ml}$ plastic pipette and passed through a $150-\mu \mathrm{m}$ wire mesh. The cell suspension was then centrifuged at $500 \times g$ for $5 \mathrm{~min}$. The supernatant was aspirated, and the cell pellet was resuspended in plating medium composed of modified Eagle's medium containing D-valine (MDV; Gibco, Grand Island, NY) containing $10 \%(\mathrm{v} / \mathrm{v})$ dialyzed fetal calf serum (dFCS; Gibco), $5 \%(\mathrm{v} /$ v) NU serum (Collaborative Research, Bedford, MA), $10 \mu \mathrm{M}$ cytosine arabinoside (Ara C), and $25 \mathrm{ng} / \mathrm{ml}$ nerve growth factor (NGF; Collaborative Research). After resuspension, cells were successively filtered through 50- and 10- $\mu \mathrm{M}$ nylon mesh filters (Small Parts, Miami, FL) to remove any remaining undigested clumps of cells and epithelial cells. Cells were plated at a density of $1 \times 10^{6}$ cells per $\mathrm{cm}^{2}$ into tissue culture dishes (Falcon, Lincoln Park, NJ) or Labtek tissue culture slides (Nunc, Naperville, IL) coated with MDV containing laminin at $25 \mu \mathrm{g} / \mathrm{ml}$ (Collaborative Research). Cultures were placed in a humidified $37^{\circ} \mathrm{C}$ incubator receiving $5 \% \mathrm{CO}_{2}$. On day 2 and every day thereafter, cells were fed with MDV containing $15 \% \mathrm{dFCS}$, gentamicin, kanamycin, NGF, and Ara $\mathrm{C}$

Immunocytochemistry. Immunohistochemistry was performed on neonatal rats the same age as those utilized in primary culture preparation. Animals were perfused with PBS and then $4 \%$ paraformaldehyde (PFA) in PBS. Olfactory tissue was dissected and postfixed in 4\% PFA for $2 \mathrm{hr}$ at room temperature. Thereafter, tissue was sunk in PBS containing $15 \%(\mathrm{w} / \mathrm{v})$ sucrose, embedded in brain paste, and sectioned on a cryostat.

For immunocytochemistry, cells were plated in two-chamber Labtek tissue culture slides previously treated with MDV containing $25 \mu \mathrm{g} / \mathrm{ml}$ 


\section{PROCEDURE}

2. mince tissue

3. centrifuge at $500 \mathrm{xg}$ for $10 \mathrm{~min}$

4. resuspend in digestion enzymes

( $1 \mathrm{ml}$ per animal)

5. incubate at $37^{\circ} \mathrm{C}$ with agitation

6. push suspension through 150 um mesh

7. triturate

8. centrifuge at $500 \mathrm{xg}$ for $10 \mathrm{~min}$

9. resuspend in plating medium

10. filter suspension through 50 um mesh

11. plate at $1 \times 10^{6}$ cells per $\mathrm{cm}^{2}$
MEDIUM

1. MEM-AIR

4. MEM-AIR containing

BSA $1 \%(w / v)$

hyaluronidase $1 \mathrm{mg} / \mathrm{ml}$

collagenase $2 \mathrm{mg} / \mathrm{ml}$

dispase $5 \mathrm{mg} / \mathrm{ml}$

DNase $5 \mathrm{ug} / \mathrm{ml}$

9. MDV containing

$10 \%$ dFCS

$5 \%$ NU serum

10 uM ara $\mathrm{C}$

antibiotics primary cultures of rat neonatal olfactory neurons. laminin. After 5-7 d in culture, the upper chamber of the slides was removed, and slides were rinsed quickly three times at $37^{\circ} \mathrm{C}$ in phosphate-buffered saline (PBS; pII, 7.3). Slides were immediately placed in PBS containing $4 \%(\mathrm{w} / \mathrm{v})$ paraformaldehyde at $37^{\circ} \mathrm{C}$ and incubated for $20 \mathrm{~min}$. Alternatively, for immunofluorescence, primary culture cells plated on slides were quickly rinsed three times with PBS at $37^{\circ} \mathrm{C}$ and placed in methanol at $-20^{\circ} \mathrm{C}$ for $15 \mathrm{~min}$. Monolayers treated in either manner were then washed three times for $5 \mathrm{~min}$ each in PBS at room temperature, permeabilized by incubation in $0.1 \%(\mathrm{w} / \mathrm{v})$ Triton $\mathrm{X}-100$ (TX-100) for $15 \mathrm{~min}$, and rinsed again three times in PBS. When chromogen was used, endogenous peroxidase activity was quenched by incubation of slides in PBS containing 2\% (v/v) hydrogen peroxide, followed by three rinses in PBS. Nonspecific staining was blocked by incubation for $1 \mathrm{hr}$ with nonimmune serum, appropriate for the secondary antibody, at a dilution of $1: 100$ in PBS containing $1 \%(\mathrm{w} / \mathrm{v})$ BSA. Slides were then incubated in PBS containing $1 \%$ BSA and primary antiserum overnight at $4^{\circ} \mathrm{C}$. The next day, the slides were rinsed three times with PBS, blocked with PBS containing $1 \%$ BSA, and incubated for $2 \mathrm{hr}$ at $25^{\circ} \mathrm{C}$ with the appropriate biotinylated secondary antibody using Vectastain kits (Vector Labs, Burlingame, CA). Slides were again washed in PBS, blocked, incubated for $1 \mathrm{hr}$ in PBS containing 1\% BSA in the avidin-biotin-horseradish peroxidase complex (Vector Labs), rinsed, and incubated for $5 \mathrm{~min}$ with the chromogen 3-amino-9-ethylcarbazole (AEC; Biomeda Corporation, Foster City, CA). For immunofluorescence, primary antiserum at the appropriate dilution was added to slides in PBS containing $1 \%$ BSA, which were then incubated overnight at $4^{\circ} \mathrm{C}$. The next day, slides were washed three times for 5 min each in PBS and incubated in PBS containing 1\% BSA and the appropriate fluorescinated or rhodaminated antibody (Jackson Immunoresearch Laboratories Incorporated, West Grove, PA). Slides were subsequently washed three times in PBS, and phase and fluorescent pictures were immediately taken.

Antisera were used at the following dilutions: monoclonal anti-vimentin antibody (Boehringer-Mannheim) at 1:3 dilution; polyclonal anti-neuron-specific enolase (NSE) antibody (IncStar, Stillwater, MN) at 1:4 dilution; polyclonal anti-S-100 antibody (IncStar) at 1:4 dilution; polyclonal anti-tubulin antibody (Dr. Douglas Murphy, Johns Hopkins
University School of Medicine, Baltimore, MD) at 1:250 dilution; polyclonal anti-olfactory marker protein (OMP) antibody (gift of Dr. Frank Margolis, Roche Institute, Nutley, NJ) at 1:300 dilution; anti-glial fibrillary acidic protein (GFAP; DAKO-Patts, Santa Barbara, CA) at 1:800 dilution; and nonimmune serum as control (Vector Labs) at 1:100 dilution.

Testing of substrates used in primary culture of olfactory neurons. To determine the role of substrate on plating efficiency and on cellular selection, a number of different substrates were utilized. Two-chamber slides were pretreated in a number of ways. For laminin coating, $1 \mathrm{ml}$ of MDV containing $25 \mu \mathrm{g} / \mathrm{ml}$ laminin was plated onto glass two-chamber slides overnight at $37^{\circ} \mathrm{C}$; before use, the slides were rinsed with MDV. For fibronectin, slides were treated with a solution containing $1 \mathrm{ml}$ of MDV containing $20 \mu \mathrm{g} / \mathrm{ml}$ fibronectin (Collaborative Research), incubated overnight at $37^{\circ} \mathrm{C}$, and rinsed with MDV prior to use. For polyornithine (PORN; Sigma Chemicals), a solution at a concentration of $1 \mathrm{mg} / \mathrm{ml}$ PORN in deionized distilled water was added to slides, incubated $1 \mathrm{hr}$ at $37^{\circ} \mathrm{C}$, rinsed twice with deionized distilled water, and rinsed once with MDV prior to use. When laminin was used on PORNtreated slides, slides were treated with POKN and then laminin in the usual manner. Coating of slides with poly-D-lysine was performed analogous to treatment with polyornithine. Heparan sulfate was diluted in MDV to a concentration of $10 \mu \mathrm{g} / \mathrm{ml}$, and $1 \mathrm{ml}$ was placed on a slide, which was then maintained overnight at $37^{\circ} \mathrm{C}$ and rinsed with deionized distilled water prior to use. Collagen (Gibco) or collagen IV (Collaborative Research) was prepared as a $50-\mu \mathrm{g} / \mathrm{ml}$ solution in deionized distilled water, and $1 \mathrm{ml}$ of this solution was utilized per slide. In the case of collagen, the solution was allowed to air dry. Collagen IV was maintained overnight at room temperature, aspirated, air dried, and then rinsed twice with deionized distilled water prior to use. When laminin was used with collagen IV, collagen IV was prepared as described, and laminin was subsequently added in the usual manner. Matrigel (Collaborative Research) was utilized according to manufacturer's instructions.

Radioimmunoassay of cAMP levels. For radioimmunoassay (RIA), primary cultures were plated on laminin-treated 24-well dishes at a density of $1 \times 10^{6}$ cells per $\mathrm{cm}^{2}$. After 5-7 d in culture, cells were treated

Figure 2. Phase-contrast microscopy of cultures of olfactory neurons. Cells were prepared and plated on laminin-coated glass slides as described in Materials and Methods. $A$, Within $2 \mathrm{hr}$ after plating, cells, which were initially rounded, extend processes and begin to migrate out of small clumps. $B$, By $24 \mathrm{hr}$ in plating, cells continue to extend processes. One process is often short and branched, while the other, extending from the other pole of the cell, is long and unbranched. $C$, By $72 \mathrm{hr}$ in culture, greater than $98 \%$ of the cclls in culturc arc bipolar, with long processcs. $D$, Low-magnification image of primary cells in culture for $72 \mathrm{hr}$. E, Cells extend long, unbranched processes, which can be visualized when stained with anti-vimentin antibodies and fluorescenated secondary antibody. Magnifications: $A-C, 1250 \times ; D$ and $E, 300 \times$. 

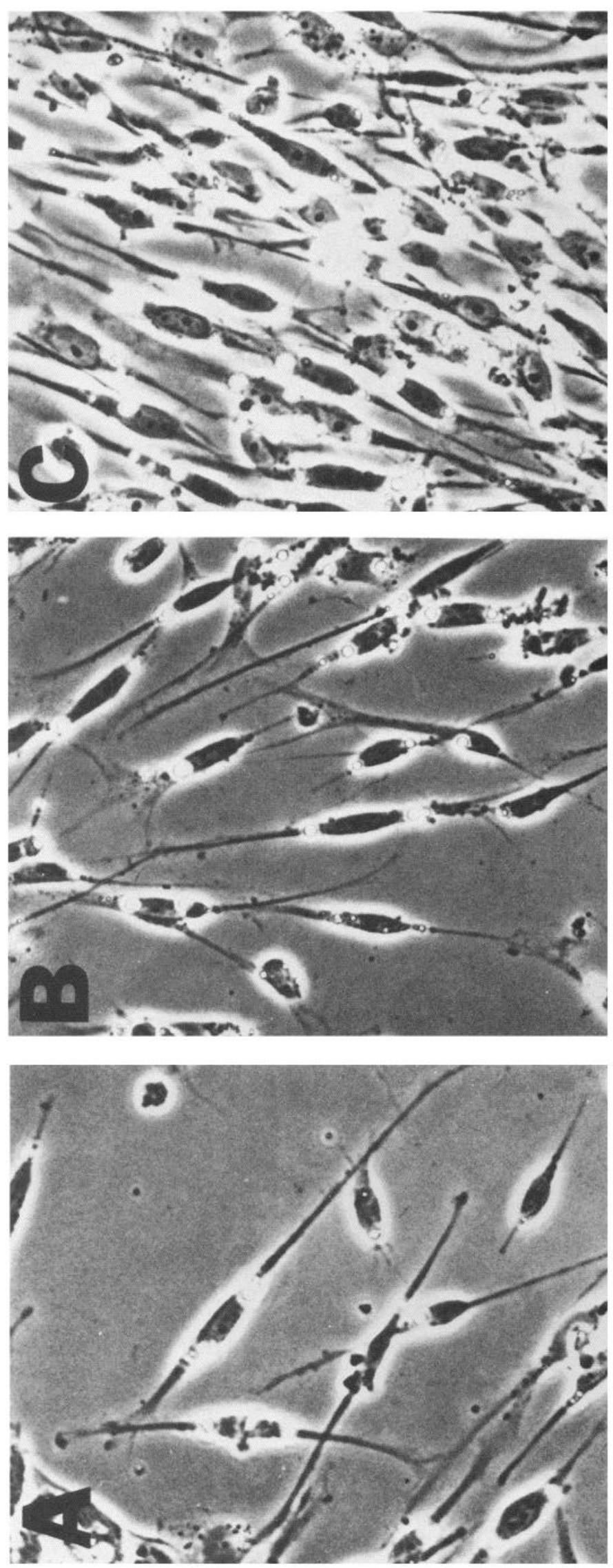
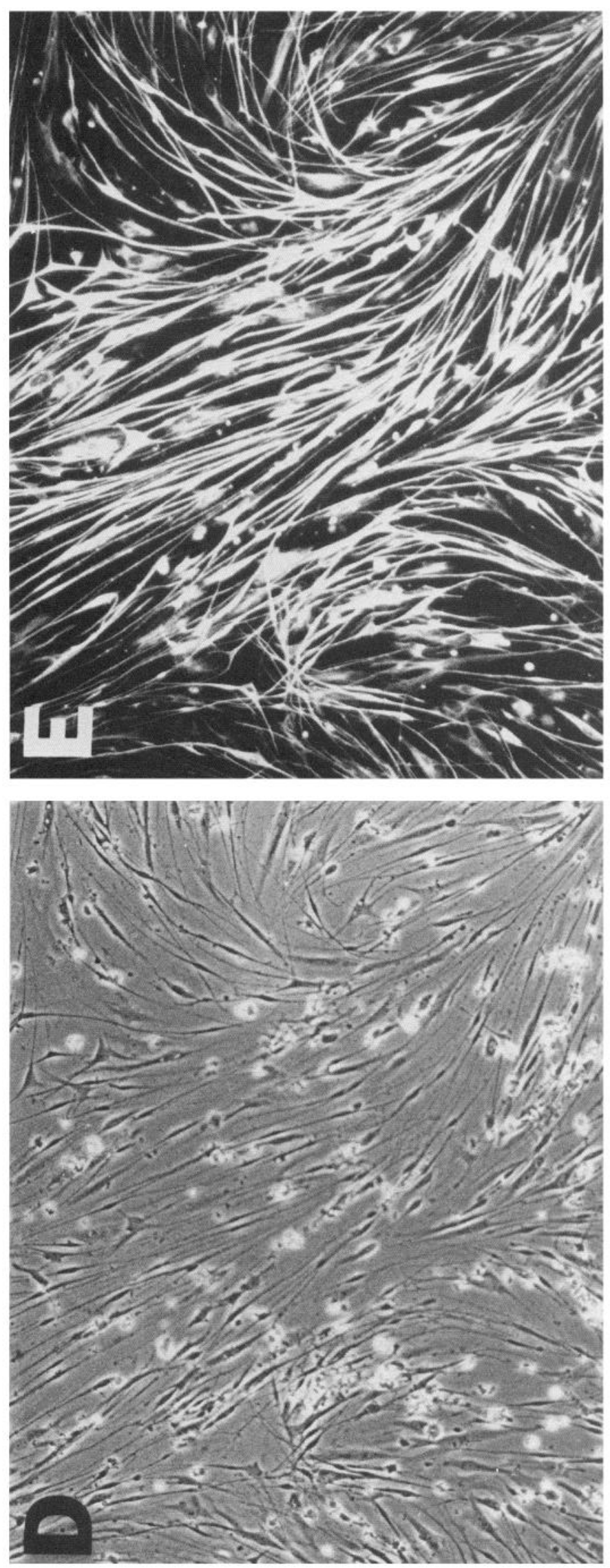

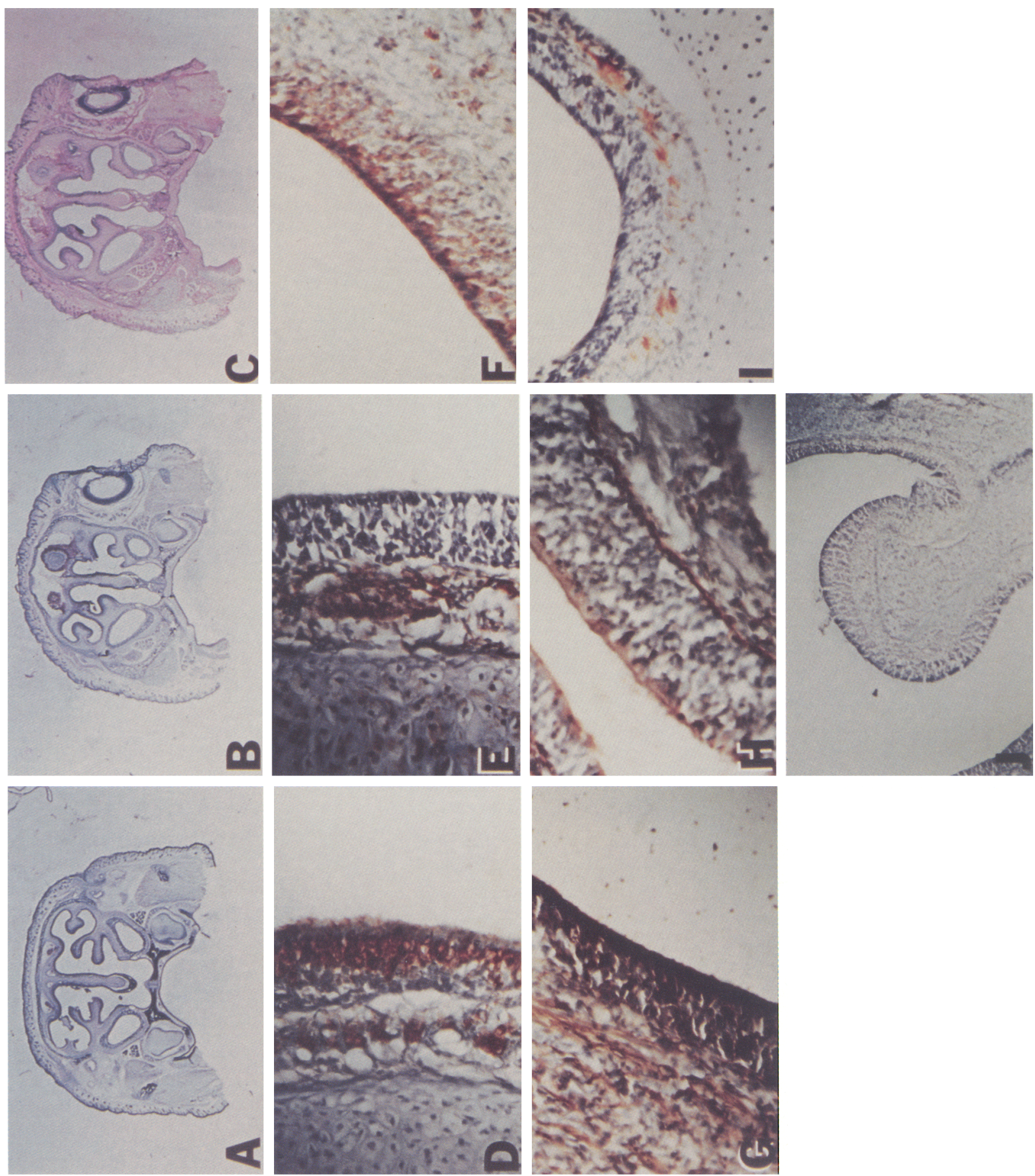
with odorants as described. The experiment was terminated by aspiration of culture medium and addition of $200 \mu \mathrm{l} 6 \%$ (w/v) trichloroacetic acid (TCA) at $0^{\circ} \mathrm{C}$. Culture wells were heated to $56^{\circ} \mathrm{C}$ in an oven for 1 $\mathrm{hr}$, scraped, sonicated, chilled, and microfuged for $30 \mathrm{sec}$. The supernatants were extracted four times with 5 vol of ether, and the etherextracted water phase was lyophilized to dryness. Samples were resuspended in $200 \mu \mathrm{l}$ of RIA-NEN buffer (New England Nuclear/DuPont, Boston, MA), and RIA assay was performed according to specifications of the cAMP kit.

Polyacrylamide gel electrophoresis and Western blotting. Sodium dodecyl sulfate polyacrylamide gel electrophoresis (SDS-PAGE) was performed according to the method of Laemmli (1970), utilizing a 14-20\% gradient. Western blotting employed the method of Speicher et al. (1980), with several modifications. Gels were transferred to nitrocellulose paper at $60 \mathrm{~V}$ for $5 \mathrm{hr}$ at $4^{\circ} \mathrm{C}$. At the end of this time, blots were rinsed in water and blocked in buffer containing $0.15 \mathrm{M} \mathrm{NaCl}, 0.05 \mathrm{M}$ Tris- $\mathrm{HCl}$, $0.05 \%$ sodium a7ide, and $2 \%(\mathrm{w} / \mathrm{v})$ RIA-grade BSA for $12 \mathrm{hr}$ at $4^{\circ} \mathrm{C}$. The next day, blots were washed three times in PBS. For rabbit antisera, the primary antiserum was placed in blocking buffer containing antiserum at the appropriate dilution, $2 \%$ BSA, and $0.05 \%$ Tween-20. Incubation was performed overnight at $4^{\circ} \mathrm{C}$. The next day, blots were washed three times in PBS containing 0.05\% Tween. Blots were incubated in ${ }^{125}$ I-protein $\mathrm{A}$ in blocking buffer containing $2 \%$ BSA and $0.05 \%$ Tween for $1 \mathrm{hr}$ at room temperature. Thereafter, blots were washed three times in PBS with $0.05 \%$ Tween and exposed to X-omat (Kodak, Rochester, NY) film. For monoclonal mouse antibodies, blots were washed in PBS without Tween and incubated in primary antibody at the appropriate dilution in blocking buffer containing $2 \%$ BSA and $3 \%$ normal serum overnight at $4^{\circ} \mathrm{C}$. The next day, blots were rinsed five times with PBS and incubated in blocking buffer containing 2\% BSA and rabbit anti-mouse $\mathrm{IgG}$ at 1:100 dilution (Jackson I abs) for $1 \mathrm{hr}$ at room temperature. Blots were again rinsed three times in PBS and mouse peroxidase anti-antiperoxidase complex (Sternberger-Meyer, Jarrettsville, MD) at 1:200 dilution in blocking buffer with $2 \%$ BSA for $1 \mathrm{hr}$ at room temperature. Blots were again rinsed three times in PBS and once in $50 \mathrm{~mm}$ Tris ( $\mathrm{pH}, 7.6)$, and then incubated in AEC for $30 \mathrm{sec}$.

Exposure of olfactory neurons to odorants. Primary cultures of olfactory neurons were plated in 24-well cluster dishes at a density of $1 \times$ $10^{6}$ cells per $\mathrm{cm}^{2}$. Cells were used between days 5 and 7 in culture. Thirty minutes before experimentation, monolayers were fed with MEM-AIR containing $0.1 \%(\mathrm{w} / \mathrm{v})$ RIA-grade BSA. Immediately prior to use, odorants were diluted from a 50 -mM stock in absolute ethanol to the final concentration specified in the experiment. At time $0,0.5 \mathrm{ml}$ of MEMAIR containing $0.1 \%$ RIA-grade BSA and odorant at twice the final concentration was added to wells. At intervals thereafter, medium was aspirated, and the reaction was quenched with $200 \mu$ lice-cold $6 \%$ TCA. Cellular monolayers were then processed as previously described.

$N G-108$ cells. NG-108 cells (a generous gift from Dr. Karen Braas, University of Vermont, Burlington, VT) were grown and maintained as previously described (Braas et al., 1983). For experimentation, cells were plated in 24-well clustered dishes and treated similarly to olfactory neurons.

\section{Results}

\section{Morphology of primary cultures of rat olfactory neurons}

Olfactory tissue from neonatal rats was collected, minced, dissociated in enzymes, and plated on chamber slides pretreated with laminin as described in Materials and Methods. Within 2 hr after plating, cells attached and began to spread (Fig. $2 A$ ).
After $24 \mathrm{hr}$ in culture, cells began to distribute more uniformly on the culture surface and extend a short, multibranched process and an opposing long, unbranched process (Fig. 2B). At $72 \mathrm{hr}$ in culture, cells reached a uniform distribution (Fig. $2 C$ ), and most non-neuronal cells had died off. Neurite outgrowth appeared random (Fig. $2 D$ ); cell processes were extremely long, about $20-50$ cell body lengths, and could be better visualized by immunofluorescence using anti-vimentin antibodies (Fig. $2 E$ ).

\section{Immunocytochemical characterization}

At low magnification (Fig. 3A-C), the olfactory epithelium appeared as frondlike projections extending towards the midlinc septum. The olfactory epithelium and the primary axons, which extended towards the bulb, stained positively for OMP (Fig. $3 A, B)$. Unlike other neuronal cells, the axons of olfactory neurons contained the intermediate filament vimentin (Schwob et al., 1986), whose immunoreactivity was apparent in olfactory primary axons as they converged upon the olfactory bulbs (Fig. $3 C$ ). At higher magnification, while OMP was evident in the epithelium containing neuronal cell bodies and the submucosal axonal processes (Fig. $3 D$ ), vimentin was localized in the submucosal region containing the primary axons (Fig. $3 E$ ). NSE immunoreactivity was also localized selectively to olfactory mucosa (Fig. $3 F$ ). Tubulin occurred diffusely throughout the mucosa, but with greater density at the luminal surface, which contains cilia (Fig. 3G). Anti-keratin antibodies stained the basal cell layer (Fig. $3 H$ ). Anti-GFAP antibodies stained the submucosal region (Fig. 3I), presumably reflecting glial-likc cclls surrounding olfactory axons. Staining of olfactory tissue with nonimmune serum is shown in Figure 3.J.

Like olfactory neurons in intact tissue, olfactory neurons in primary culture stained positively using anti-OMP antibodies (Fig. $4 A, B$ ), anti-vimentin antibodies (Fig. $4 C, D$ ), and anti-NSE antibodies (Fig. $4 G, H$ ). No staining of primary cultures was seen using anti-S-100 antibody (Fig. $4 E, F$ ). Occasional GFAP-positive cells were seen (Fig. $4 I, J$ ), which have distinctive morphology; none of the bipolar cells stained positively for GFAP. No staining was seen when nonimmune serum was used in place of primary antiserum (Fig. $4 K, L$ ). Thus, cultures of rat primary olfactory neurons stained specifically for those markers found in neurons in vivo. Immunofluorescence was used for primary cultures because positive staining in the processes was not adequately demonstrated by peroxidase.

To confirm the specificity of staining in both tissue sections and in primary cultures of olfactory neurons, Western blot analysis was performed (Fig. 5). Tissue was collected from olfactory bulb, olfactory epithelium, and primary olfactory cultures and prepared as described in Materials and Methods. Extract (100 $\mu \mathrm{g} / \mathrm{lane}$ ) was loaded on a 14-20\% SDS-PAGE gel, electrophoresed, and transferred to nitrocellulose paper as previously de-

Figure 3. Immunocytochemistry of neonatal rat nasopharyngeal sections. Tissue was perfused, isolated, and processed as described in Materials and Methods. $A$, Low-power view of coronal section stained for OMP. Positive staining (red) is seen as fibers converge on the olfactory bulbs and in the olfactory epithelium. $B, \Lambda$ more caudal section demonstrates OMP positivity in the epithelium and on fibers converging on the bulb. $C$, Low-power coronal sections stained for vimentin. Diffuse positivity is seen, as well as positive staining in the axons of the primary olfactory neurons as they converge on the olfactory bulbs. $D$, Staining of olfactory epithelium for OMP. Positive staining is seen along the olfactory epithelium and in the submucosal region where olfactory axons traverse. $E$, Staining for vimentin. Positive staining is seen in the submucosal region where olfactory neurons traverse. $F$, Staining of olfactory epithelium for NSE. Staining is visualized in the olfactory epithelium. $G$, Staining of olfactory tissue for tubulin. Very concentrated staining is seen at the level of the apical epithelium, where cilia are present. $H$, Staining of olfactory epithelium with anti-keratin antibodies. Staining visualizes the layer of basal cells. $I$, Staining of olfactory epithelium for GFAP reveals discrete staining in the submucosal region, where GFAP-positive cells may serve to ensheathe olfactory axons. $J$, Staining with nonimmune control. Magnifications: $A-$ $C, 5 \times ; D-I, 250 \times ; J, 100 \times$. 

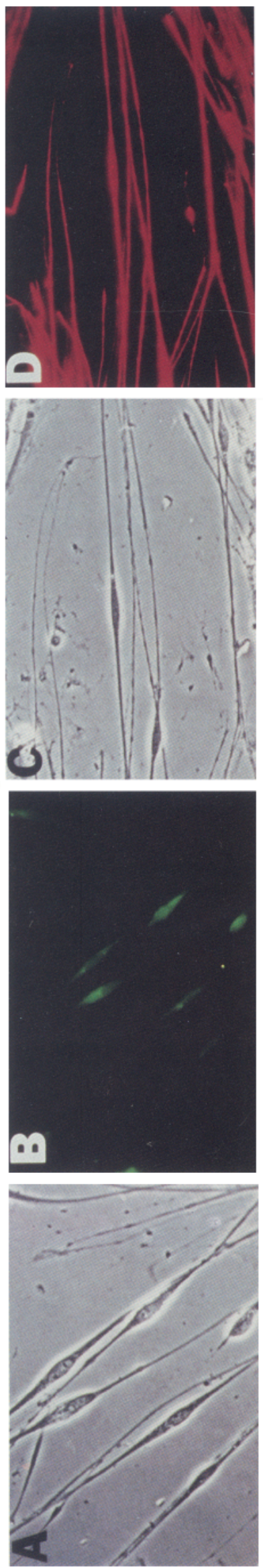
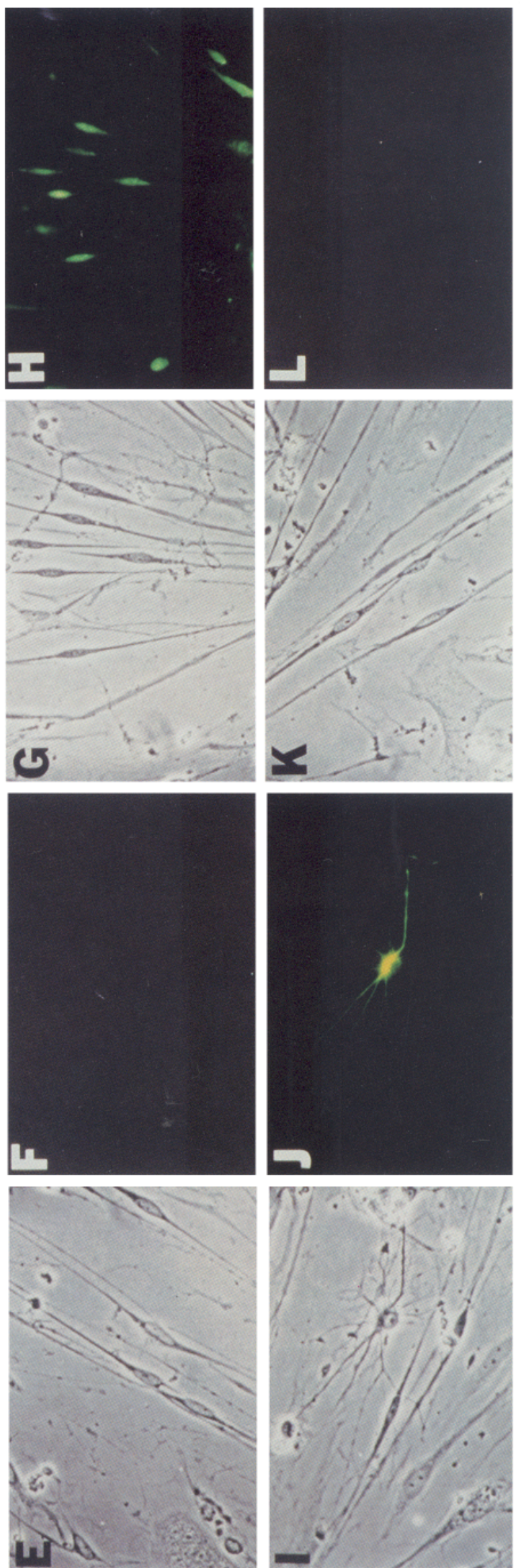

起崖出

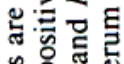

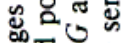

西它

ज

的品

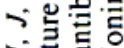

请的

证可

Q

Q

든

응

는 르을 的㱐 문 E  जी $\checkmark$ 옹 心

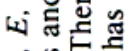
U ड家㣢 需 3 议

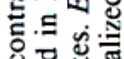
\% \%

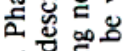
的 익 ํㅣㄹ 응 응 可 을 ब린 엉니 政 논 可兘 氺.음 ․ㅡ응 들. 和出 융. 웡 密 क ․ㅝ웡 3.5 들 $\overline{\mathrm{c}}$. 낭 중. 猔兽 胥完. ह 능휴 के $\forall$ 过U: ั 으을 

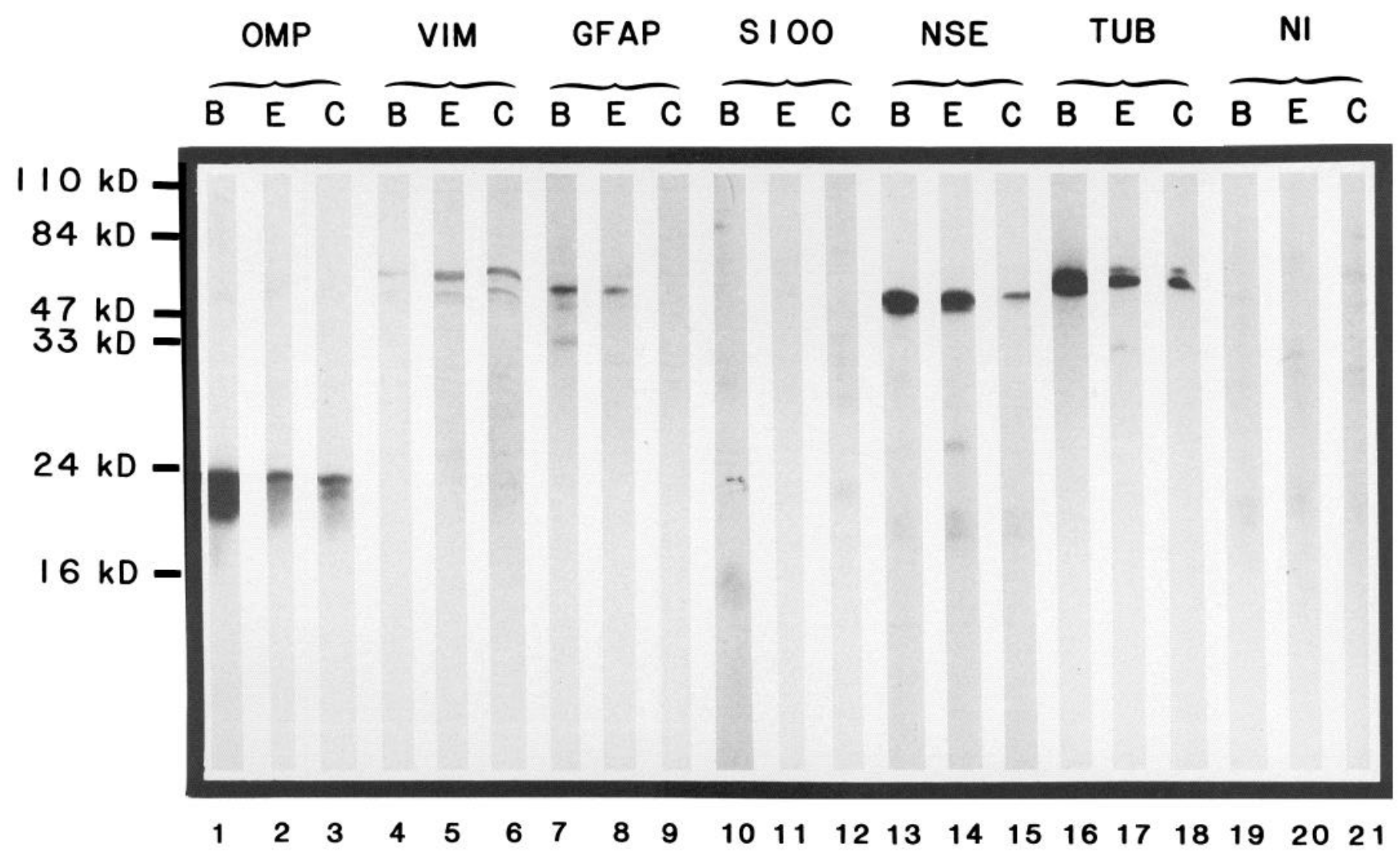

Figure 5. Western blot analysis of extracts of olfactory neurons in culture. Tissue from olfactory bulb $(B)$, olfactory epithelium $(E)$, or primary cultures of olfactory neurons $(C)$ were prepared as described in Materials and Methods. Extracts were run on PAGE, and Western blot analysis was performed as described in Materials and Methods. All three extracts show detectable OMP (lanes $1-3)$. Likewise, vimentin (VIM) is present in all three tissues (lanes 4-6). GFAP is detectable in olfactory bulb and epithelium, but not in cultures (lanes 7-9). S-100 protein (S100) is detectable in olfactory bulb, but not in olfactory epithelium or cultured material (lanes 10-12). Both NSE (lanes 13-15) and tubulin (TUB; lanes 16-18) are detectable in all 3 tissues. No staining is seen with nonimmune serum (NI; lanes 19-21).

scribed. Blots were incubated with antibodies against OMP(Fig. 5 , lanes 1-3), anti-vimentin antibodies (lanes 4-6), anti-GFAP antibodies (lanes 7-9), anti-S-100 antibodies (lanes 10-12), antiNSE antibodies (lanes 13-15), anti-tubulin antibodies (lanes 1618 ), and nonimmune serum in place of primary antiserum (lanes 19-21). Antibodies against OMP recognized a band of appropriate molecular weight in all three tissues. Anti-vimentin antibodies recognized a band of appropriate molecular weight in bulb and olfactory epithelium extract, as would be expected given the mesenchymal elements present in these tissues, as well as in the primary olfactory cells, whose axons contain vimentin. Although antibodies against GFAP detected a band of appropriate mobility in olfactory bulb and olfactory epithelium, no such band was seen upon incubation with olfactory-cultured extracts. While immunofluorescence (Fig. $4 I, J$ ) demonstrated the presence of occasional GFAP-positive cells, levels of GFAP were presumably too low to be detected by Western blotting. Antibodies against S-100 protein recognized a band of appropriate molecular weight in olfactory bulb, but not in olfactory epithelium or primary cultures. NSE immunoreactivity of appropriate molecular weight was evident in olfactory bulb, olfactory epithelium, and primary cultures. Antibodies against tubulin detected a doublet of appropriate molecular weight in all three tissues, while nonimmune serum failed to identify the major bands in any of the three extracted tissues. Thus, Western blot analysis confirmed the specificity of staining seen by immunocytochemistry of primary cultures of rat olfactory neurons.

\section{Immunocytochemistry of olfactory mucosal components removed by filtration}

The procedure to prepare olfactory neurons from dissociated cells of olfactory mucosa included entrapment of epithelial cells on the $50-\mu \mathrm{m}$ filter just prior to plating. Perhaps because of differences in extracellular matrix components, the epithelial cells, which probably included epithelial and sustentacular cells, remained associated or reassociated so that they were trapped by filtration. Some neurons were trapped, as well. Epithelial cells generally appear flat and polygonal, but after 5-7 d in cultures, they may appear fusiform, though they did not extend processes similar in length or diameter to the primary neurons seen in the flow through. The epithelial cells trapped on the filters were characterized immunocytochemically (Fig. 6). Cellular material trapped on filters was eluted into plating medium and plated in a similar manner to olfactory neurons. Fixation and immunocytochemical staining was performed as described in Materials and Methods. In contrast to olfactory neurons, epithelial cells do not stain for vimentin (Fig. $6 A, B$ ). An occasional putative neuronal cell was retained along with the epithelial cells and did stain for vimentin (Fig. 6A,B). Epithelial cells (cells demonstrating keratin immunoreactivity) did not 

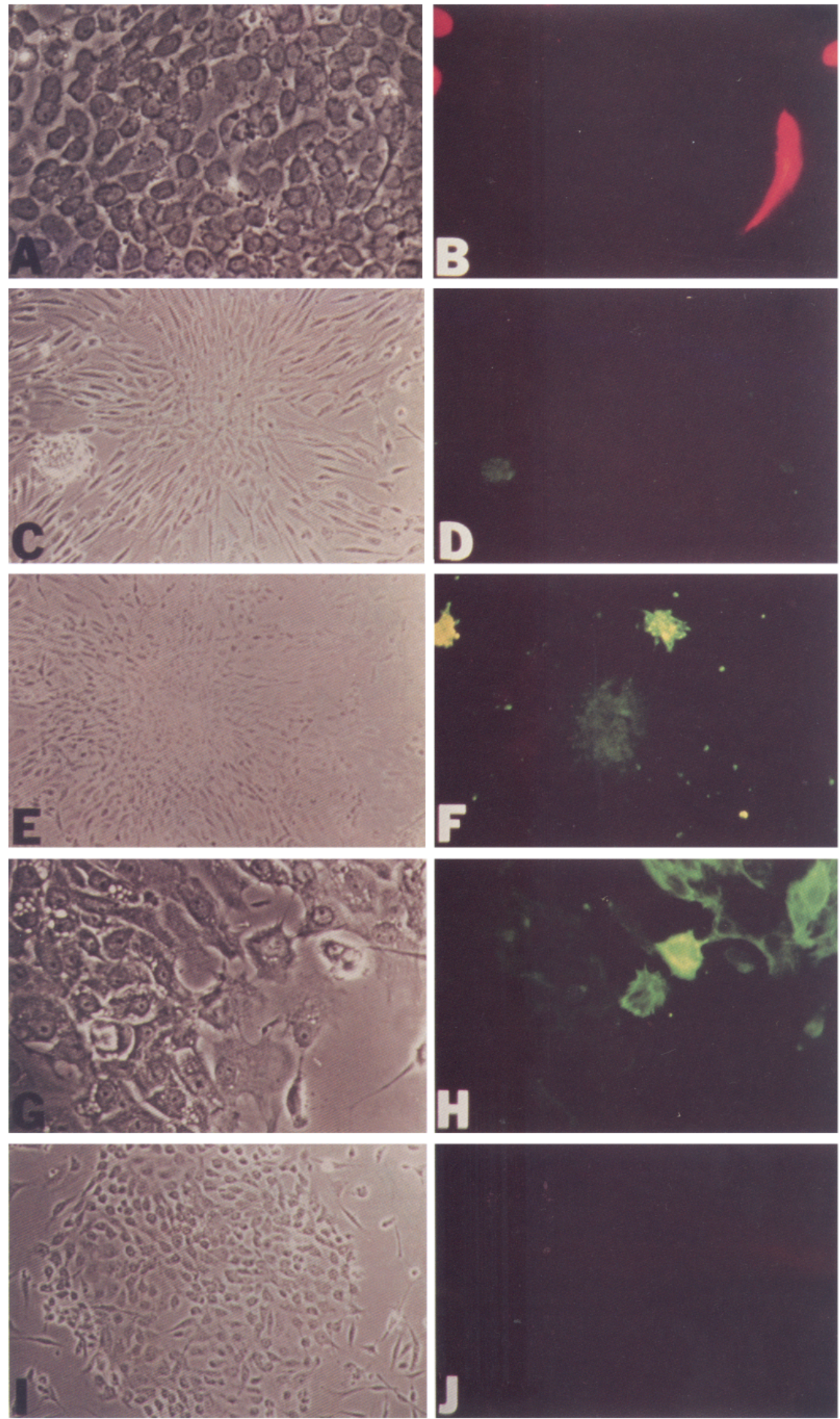
stain for OMP (Fig. 6C,D). Basal cells were apparently trapped on filters, as well, because small clumps of cells stained positively for keratin found in basal cells in vivo (Fig. $6 E-H$ ). No staining was seen using nonimmune serum (Fig. $6 I, J$ ). Thus, a substantial part of cellular selection was achieved by filtration, which apparently trapped the majority of epithelial cells. Although after a week in culture these cells acquired spindle-shaped morphology, they were initially rounded and polygonal and therefore could easily be differentiated from neurons. In addition, their staining patterns differed from neuronal cells.

\section{Substrate testing for primary cultures of olfactory neurons}

Although laminin gave reproducible and significant neurite outgrowth, a number of different substrates were tested for their ability to support neurite extension and for plating efficiency. Primary cultures were prepared as described in Materials and Methods and plated onto a number of different substrates depicted by phase contrast as well as immunofluorescence with antivimentin antisera (Fig. 7). Cells maintained on laminin (Fig. $7 A, B$ ) resembled those grown on fibronectin (Fig. $7 C, D$ ), though the processes were shorter with the latter substrate. Combining laminin and fibronectin (Fig. $7 E, F$ ) provided an appearance similar to laminin alone. Cells maintained on poly-D-lysine (Fig. $7 G, H)$ displayed poor plating efficiency and minimal process outgrowth, while with PORN (Fig. $7 I, J$ ) they appeared only slightly better than with poly-D-lysine. Laminin and PORN together (Fig. $7 K, L$ ) afforded better plating efficiency and neurite outgrowth, which remained inferior to laminin or fibronectin. Heparan sulfate (Fig. $7 M, N$ ) yielded similar results to PORN. Although collagen (Fig. 7O,P) allowed somewhat better plating efficiency than poly-D-lysine, PORN, or heparan sulfate, process outgrowth was still stunted, and plating efficiency was not optimal. Collagen IV (Fig. $7 Q, R$ ) yielded improved neurite outgrowth and plating efficiency, which was still inferior to fibronectin or laminin. Utilization of laminin and collagen IV together (Fig. $7 S, T$ ) yielded better plating efficiency and neurite outgrowth, which was inferior to laminin or fibronectin. Thus, of all substrates tested, laminin consistently provided optimal plating efficiency and, therefore, was used for subsequent experimentation.

Matrigel was also examined as a substrate (Fig. 8). On laminin, cells extended neurites in a random fashion, with no tendency to reaggregate (Fig. $8 A$ ). In contrast, when duplicate suspensions of cells were plated onto matrigel, the cells aggregated over the next 48 hr to form clusters (Fig. 8B,C). Some cells extended perpendicularly from these clusters, with the extending process demonstrating multiple short, branched processes. Thus, in a 3-D matrix, these culture cells assumed a polarity, with structures representing putative cilia extending apically.

\section{Effect of NGF on olfactory neurons}

NGF is thought to play an important role in neuronal maturation and differentiation (for review, see Misko et al., 1987;
Levi et al., 1988). To investigate the role of NGF on olfactory neuronal survival and neurite extension, primary cultures were plated in the absence or presence of NGF at concentrations of up to $25 \mathrm{ng} / \mathrm{ml}$ (Fig. 9). Primary cultures were plated into twochamber slides. An aliquot of medium with (Fig. $9 A$ ) or without (Fig. $9 B$ ) NGF was added after cells were plated. Although both sets of cells initially extended processes with good plating efficiency, by $3 \mathrm{~d}$ in culture, those cells maintained without NGF lost process extension, and cell viability was decreased by approximately $85 \%$. Therefore, NGF apparently affects both olfactory neuronal survival and neurite extension in culture.

\section{Effect of odorants on intracellular cAMP levels}

After 5-7 d in primary culture, olfactory neuronal cells were exposed to odorants, and cAMP levels were assayed. To avoid transient changes in intracellular cAMP levels caused by feeding, the medium was changed to $0.5 \mathrm{ml}$ MEM-AIR containing $0.1 \%$ (w/v) RIA-grade BSA $30 \mathrm{~min}$ before use. At time 0, cultures received an additional $0.5 \mathrm{ml}$ MEM-AIR with or without 10 $\mu \mathrm{M}$ 2-isobutyl-3-methoxypyrazine (IBMP). At various times thereafter, the entire medium was aspirated, and the reaction was quenched by addition of $6 \%$ ice-cold TCA, as described in Materials and Methods. Cellular extracts were processed, and RIA for cAMP was performed as described.

IBMP elicited a rapid, transient rise in intracellular cAMP levels (Table 1). The maximum increase seen was approximately threefold over control levels. Similar treatment of NG-108 cells did not alter cAMP levels.

\section{Discussion}

A fundamental problem in the study of olfactory signal transduction has been obtaining adequate amounts of olfactory neurons in culture for study. Several workers have previously attempted to prepare primary cultures of olfactory neurons. Initial attempts relied upon the in vitro culture of the entire olfactory epithelium (Noble et al., 1984; Gonzales et al., 1985). While this system may be useful to study neurite outgrowth, it is too heterogeneous to study signal transduction. Kleene and Gesteland (1981) dissociated the frog olfactory epithelial cells into single cells using $N$-ethylmaleimide, but the cells lost electrical excitability. Hirsch and Margolis (1979) used enzymatic dissociation and mechanical disruption to obtain partially purified olfaction cells but with a limited yield precluding biochemical studies. Calof and Chikaraishi (1989) employed enzymatic dissociation to isolate olfactory neuronal precursors and evaluate proliferation and differentiation in vitro. Pixley and Pun (1990) have isolated neonatal rat olfactory tissue and have identified excitable cells in culture that were responsive to odorants.

Coon and co-workers (Coon et al., 1989) have reported continuous, apparently monoclonal cultures of olfactory cells with neuronal properties including responsiveness to odorants. Because these cell lines are clonal, they may not encompass the entire spectrum of odorant responsiveness.

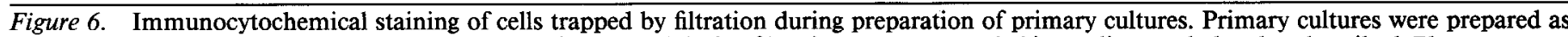

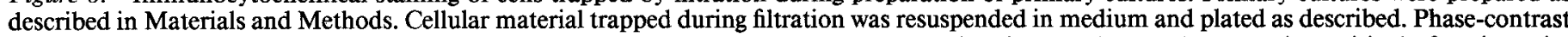

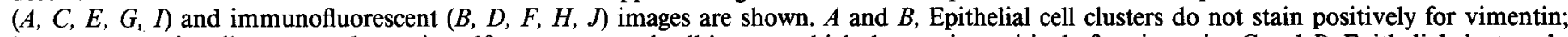

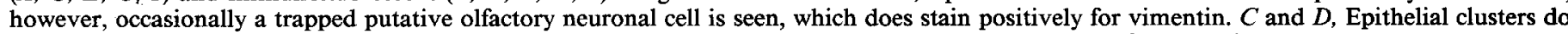

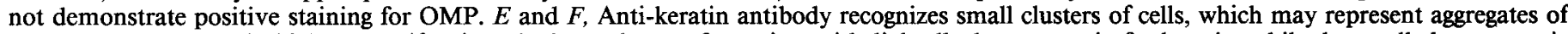

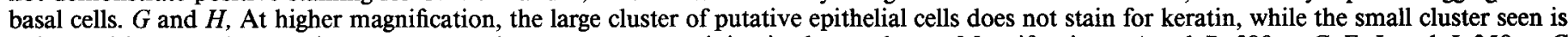

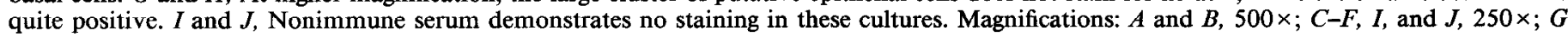
and $H, 700 \times$. 

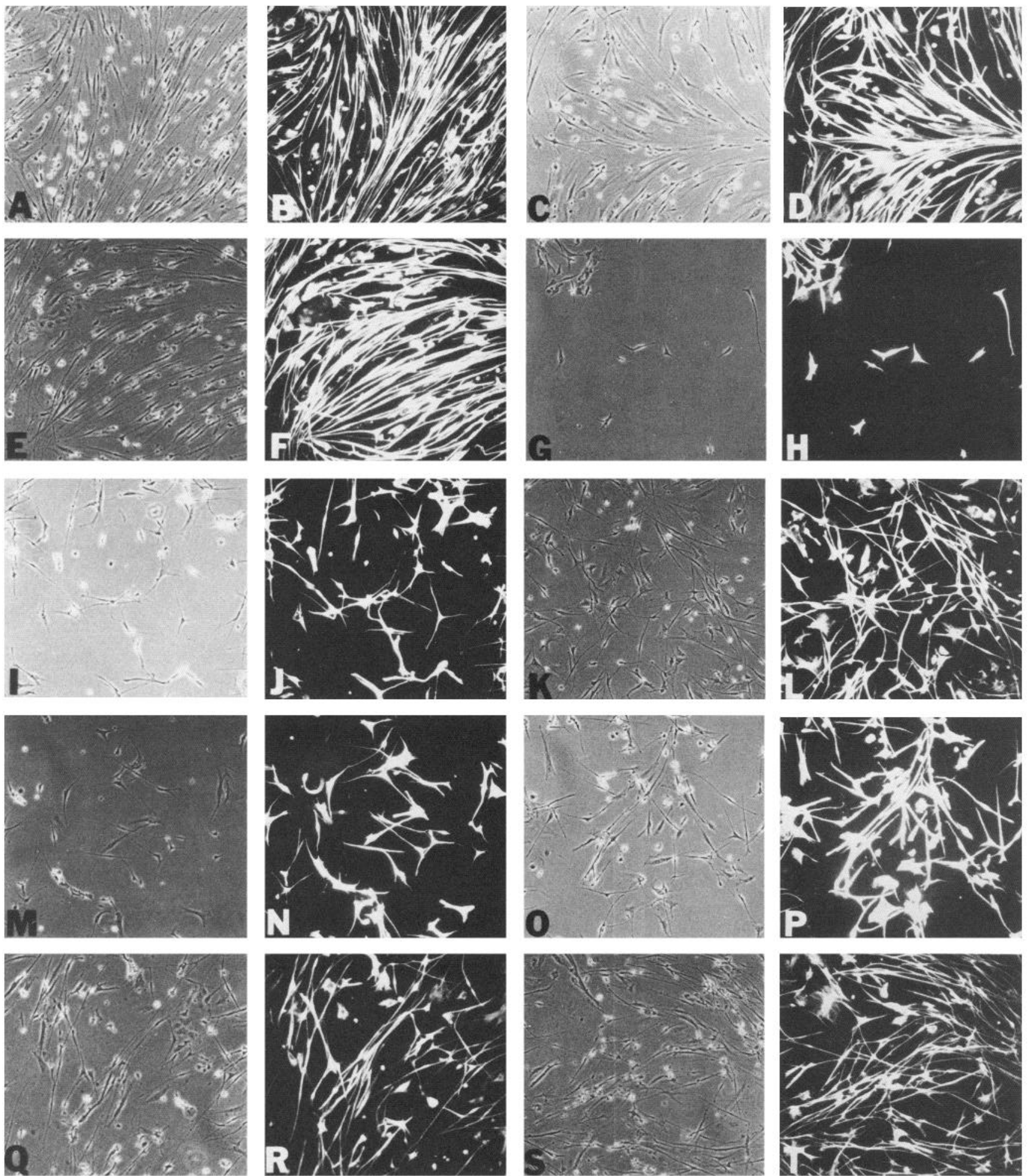

Figure 7. Evaluation of substrate for morphology and plating efficiency of olfactory neurons. Cell cultures were prepared and plated on substrates as described in Materials and Methods. Phase-contrast $(A, C, E, G, I, K, M, O, Q, S)$ and immunofluorescent $(B, D, F, H, J, L, N, P, R, T)$ images are shown. $A$ and $B$, Laminin fosters extension of long neurites and high plating efficiency. $C$ and $D$, Fibronectin treatment results in comparable neurite extension; however, it is accompanied by a higher proportion of polygonal cells. $E$ and $F$, Utilization of fibronectin and laminin does not enhance cell density or neurite extension. $G$ and $H$, Poly-D-lysine treatment results in poor plating efficiency and neurite outgrowth. $I$ and $J$, PORN treatment is similar to poly-D-lysine treatment. $K$ and $L$, Laminin and PORN in combination result in some enhancement, but not as dramatic as laminin alone. $M$ and $N$, Heparan sulfate treatment is comparable to PORN. $O$ and $P$, Collagen pretreatment results in relatively poor cellular density and minimal neurite outgrowth. $Q$ and $R$, Collagen IV is somewhat better than collagen. $S$ and $T$, Collagen IV and laminin treatment results in some enhancement over collagen IV, but is not comparable to laminin alone. Magnification: $1000 \times$. 

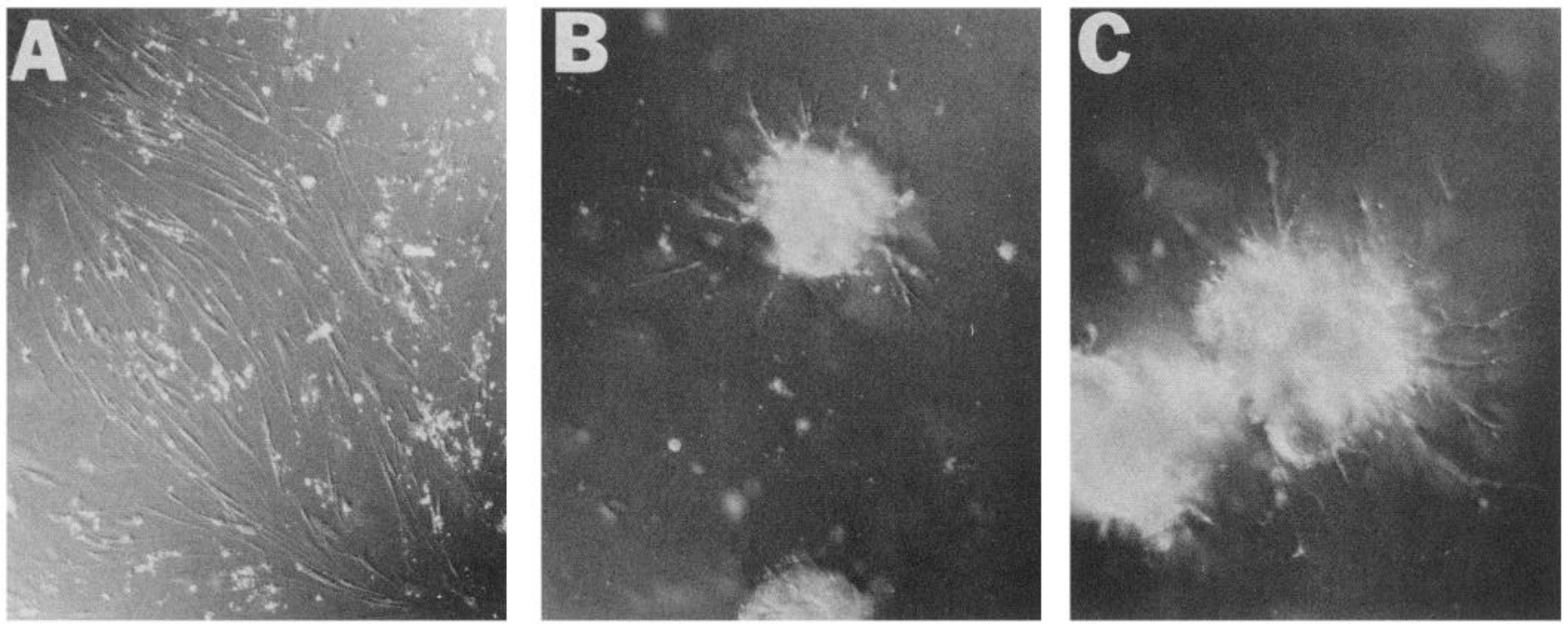

Figure 8. Plating of primary cultures onto matrigel results in cellular aggregation. Cell cultures were prepared and plated as described in Materials and Methods. $A$, When plated onto laminin, neuronal cultures demonstrate typical morphology and bipolarity. $B$, However, when plated into matrigel, cells reaggregate and form clusters with apically extending short processes. $C$, At higher magnification, these processes are multiple, extending from a single apical process. Magnification: $900 \times$.
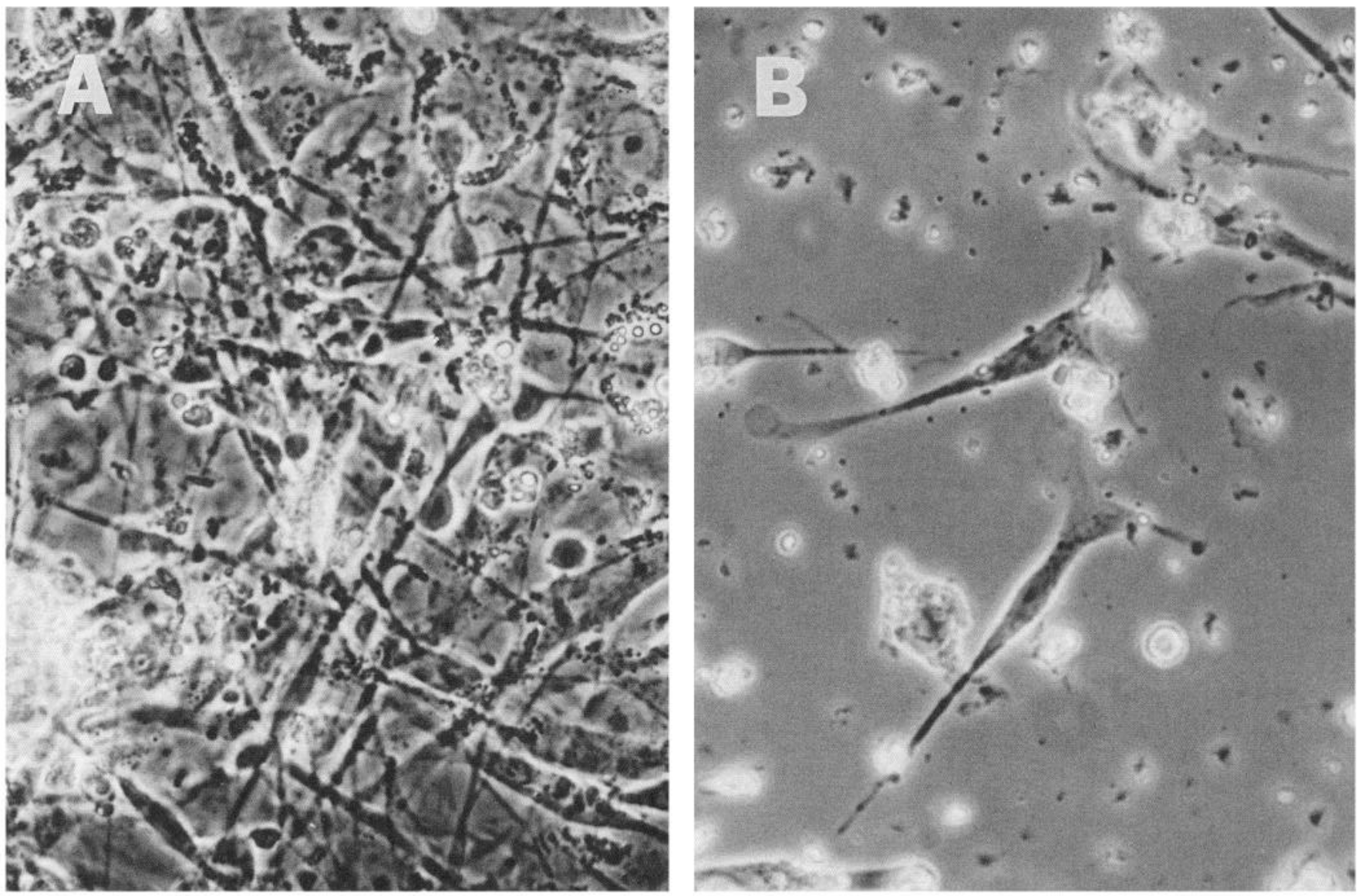

Figure 9. Effect of NGF olfactory neuron survival. Olfactory neurons were grown as described in Materials and Methods, either with $(A)$ or without $(B) \mathrm{NGF}$ at a concentration of $25 \mathrm{ng} / \mathrm{ml}$. Although cell attachment is comparable, within $48 \mathrm{hr}$ of plating cell viability dramatically decreases and neurites disappear. Magnification: $250 \times$. 


\begin{tabular}{ll}
\hline Table 1. Effect of odorant on cAMP levels in culture cells \\
& $\begin{array}{l}\text { cAMP } \\
\text { (\% control } \pm \text { SEM) }\end{array}$ \\
Timc (min) & \\
\hline Primary olfactory neurons & $350 \pm 160$ \\
0.5 & $250 \pm 92$ \\
1.0 & $270 \pm 113$ \\
5.0 & $175 \pm 47$ \\
15 & \\
NG-108 cells & $103 \pm 19$ \\
0.5 & $94 \pm 32$ \\
1.0 & $99 \pm 16$ \\
5.0 & $70 \pm 41$ \\
15 &
\end{tabular}

Primary olfactory neuronal and NG-108 cell cultures were prepared as described in Materials and Methods. All cell types were exposed acutely to $10 \mu \mathrm{M}$ IBMP and harvested for RIA as described in Materials and Methods. Results are presented as level of cAMP relative to control (mock treatment without odorant). A a concentration of $10 \mu \mathrm{M}$, IBMP caused a rapid, transient increase in intracellular cAMP in primary olfactory neurons, which did not occur in NG-108 cells.

We combined mild enzymatic dissociation with mechanical dissociation. We further selected for neuronal cells by employing selective medium and using laminin as a substrate.

Our cultures appeared to contain predominantly (greater than $98 \%$ ) olfactory neurons by a number of criteria. As is appropriate for these neuronal cells in culture, they contained OMP, NSE, and vimentin. Our cells did not display S-100, GFAP, or keratin, markers for non-neuronal cells. OMP occurs uniquely in mature olfactory neurons in the olfactory epithelium (Margolis, 1985; Baker et al., 1989). NSE is selectively localized to neurons. $\mathrm{N}-\mathrm{CAM}$ is also of potential use in characterizing these cells. Although neurons in the mammalian CNS uniquely possess neurofilament protein as their intermediate filament protein, olfactory neurons contain vimentin. Our cells had vimentin but not neurofilament protein (data not shown). Although these cultures were essentially pure preparations of olfactory ncurons, the method cannot discriminate potentially diverse functional classes of receptor cells.

Low concentrations of IBMP, a potent odorant, elicited a pronounced, transient increase in cAMP levels in these cells, but not in neuroblastoma cells. In other studies with these same cells, we have observed similar effects with other odorants on both cAMP levels and adenylyl cyclase activity. The relative potencies of odorants in enhancing adenylyl cyclase parallels psychophysical potency. Thus, IBMP, one of the most potent odorants known, elicits $50 \%$ of maximal adenylyl cyclase augmentation at $1 \mathrm{nM}$, while comparable $\mathrm{ED}_{\mathrm{so}}$ values for citralva, isovaleric acid, are 1-10 $\mu \mathrm{M}$, (Ronnett et al., in press). Using rapid stop-flow techniques, Breer et al. (1990) recently observed rapid responses of cAMP levels to odorants in preparations of olfactory cilia. However, the elevation of cAMP levels lasted hundreds of milliseconds in isolated cilia, whereas the signal lasts over $1 \mathrm{~min}$ in intact cells. This may reflect differences in the systems studied. Phosphoinositide turnover is enhanced by odorants in olfactory cilia (Breer et al., 1990). Our cultures contained substantial amounts of $\mathrm{IP}_{3}$ receptor immunoreactivity, and their $\mathrm{IP}_{3}$ production was increased by odorants (G. V. Ronnett and S. H. Snyder, unpublished observations). The responsiveness to odorants of these primary cultures of olfactory cells indicates that they possessed physiologic odorant receptors. These might occur on the cell bodies or, alternativcly, in processes.
Several aspects of the purification procedure selected for olfactory neurons. Epithelial cells appeared to aggregate/reaggregate during purification, thereby remaining in larger clumps, which could be filtered out. On the other hand, a majority of olfactory neurons dissociated as single cells and passed through the filters. Cells were plated in MDV, which permits only epithelial cells to survive (Gilbert et al., 1986). This medium has been previously used (Oster-Granite and Herndon, 1978) to select for neuronal cells. Fibroblasts and other mesenchymal cells, frequently the major contaminating species in culture, were thereby effectively eliminated. The use of laminin as a substrate also aided in selecting neuronal cells, because fibroblasts did not appear to attach. Ara $\mathrm{C}$ inhibits the growth of dividing cells, thereby selecting mature, nondividing cells. In summary, these primary cultures appeared to represent olfactory neurons on the basis of their morphology and expression of markers that are selective for neurons. Their responsivity to odorants indicates retention of functional, physiologic odorant receptors. The cells should facilitate investigations of mammalian olfaction.

\section{References}

Baker H, Grillo M, Margolis FL (1989) Biochemical and immunocytochemical characterization of olfactory marker protein in the rodent central nervous system. J Comp Neurol 285:246-261.

Braas KM, Childers SR, U'Prichard DC (1983) Induction of differentiation increases Met5-enkephalin and Leu5-enkephalin content in NG108-15 hybrid cells: an immunocytochemical and biochemical analysis. J Neurosci 3:1713-1727.

Breer H, Boekhoff I, Tarellus E (1990) Rapid kinetics of second messenger formation in olfactory transduction. Nature 345:65-68.

Calof AL, Chikaraishi DM (1989) Analysis of neurogenesis in a mammalian neuroepithelium: proliferation and differentiation of an olfactory neuron precursor in vitro. Neuron 3:115-127.

Coon HG, Curcio F, Sakaguchi K, Brandi ML (1989) Cell cultures of ncuroblasts from rat olfactory cpithelium that show odorant responses. Proc Natl Acad Sci USA 86:1703-1707.

Gilbert SF, Oster-Granite ML, Kirby W, Durie D, Lyons D, Greene E (1986) Selective culture medium enhances survival of neuroblasts from postnatal rodent brain. Brain Res 16:853-860.

Gonzales F, Farbman AI, Gesteland RC (1985) Cell and explant culture of olfactory chemoreceptor cells. J Neurosci Method 14:77-90.

Graziadei PPC (1971) The olfactory mucosa of vertebrates. In: Handbook of sensory physiology, Vol I (Beidler LM, ed), pp 27-58. Berlin: Springer.

Hirsch JD, Margolis FL (1979) Cell suspensions from rat olfactory neuroepithelium: biochemical and histochemical characterization. Brain Res 161:277-291

Kleene SJ, Gesteland RC (1981) Dissociation of frog olfactory epithelium with $N$-cthylmaleimide. Brain Res 229:536-540.

Laemmli UK (1970) Cleavage of structural proteins during the assembly of the head of bacterio phage T-4. Nature 227:680-685.

Lancet D (1986) Vertebrate olfactory reception. Annu Rev Neurosci 9:329-355.

Levi A, Biocca S, Cattaneo A, Calissano P (1988) The mode of action of nerve growth factor in PC12 cells. Mol Neurobiol 2:201-226.

Margolis FL (1985) Olfactory marker protein: from PAGE band to cDNA clone. Trends Neurosci 8:542-546.

Misko TP, Radeke MJ, Shooter EM (1987) Nerve growth factor in neuronal development and maintenance. J Exp Biol 132:177-190.

Noble M, Mallaburn PS, Klein N (1984) The growth of olfactory neurons in short-term cultures of rat olfactory epithelium. Neurosci Letts 45:193-198.

Oster-Granite ML, Herndon RM (1978) Studies of cultured human and simian fetal brain cells. I. Characterization of the cell types. Neuropathol Appl Neurobiol 4:429-442.

Pixley SK, Pun RYK (1990) Cultured rat olfactory neurons are excitable and respond to odors. Dev Brain Res 53:125-130. 
Ronnett GV, Parfitt DJ, Hester LD, Snyder SH (in press) The odorantsensitive adenylcyclase: rapid, potent activation and desensitization in primary olfactory neuronal cultures. Proc Natl Acad Sci, in press. Schwob JE, Farber NB, Gottlieb DI (1986) Neurons of the olfactory epithelium in adult rats contain vimentin. J Neurosci 6:208-217.
Snyder SH, Sklar PB, Pevsner J (1988) Molecular mechanisms of olfaction. J Biol Chem 263:13971-13974.

Speicher DW, Morrow JS, Knowles WJ, Marchesi VT (1980) Identification of proteolytically resistant domains of human erythrocyte spectrin. Proc Natl Acad Sci USA 77:5673-5677. 